\title{
Including Organizational Cultural Parameters in Work Processes ${ }^{1}$
}

\author{
Holly A. H. Handley and Nancy J. Heacox \\ Pacific Science \& Engineering Group, Inc. \\ 9180 Brown Deer Road \\ San Diego, CA 92121
}

\begin{abstract}
Recent work in modeling decision-making work processes has focused on including the national culture of individual decision-makers in order to emphasize the differences in decision criteria between decision-makers of different nationalities. In addition to nationality, a decision-maker is also a member of an organization and brings this organizational culture to his role in the work process, where it may also affect his task performance. In order to represent the organizational impact on the work process, five organizational cultural parameters were identified and included in an algorithm for modeling and simulation of cultural difference in human decision-making. While the five modifiers are not orthogonal, each captures a unique aspect of the organizational impact. The organizational cultural parameters are Authority Distance, Interface Culture, Command Authority, Doctrine, and Hierarchical Arrangement. This allows the prediction of outcome changes for a work process when interacting decision-makers have similar national cultures but whose organizational culture is different. The effect of including these parameters was illustrated on a Public Affairs Office process that integrated U.S. and U.K. decision-makers.
\end{abstract}

\subsection{Introduction}

Current research in the field of modeling human decision-making in work processes has attempted to include aspects of a decision-maker's national culture in order to more completely represent his decision criteria. However, a decision-maker is also a member of an organization and is accustomed to fulfilling a role in that organization's work process. While an organization's culture is conceptually tied to the predominant national culture of the organization, it manifests itself in different ways; e.g., different types of roles a decision-maker may play in an organization, different communication patterns at the nodes where the decision-makers fill billets, and varying performance metrics that are expected to be met. The culture of this organization, in addition to that of the individual decision-maker, can be represented by parameters in the work process in which the decision-maker is participating.

This study, based on research for modeling and simulation of cultural difference in human decision-making (Handley and Heacox, 2003), separates the cultural influences at the decision-maker and organizational levels. While the initial research focused on national culture at the decision-maker level, this current study is directed at evaluating the impact that organizational cultural characteristics have on the work process outcomes.

\footnotetext{
${ }^{1}$ This work was supported by the Office of Naval Research under contract N00014-03-M-0241
} 
Combined military operations are becoming a standard operational mode, which often entails staff being assigned out of their 'home' organization to work with staff from another organization or even multiple organizations. As these personnel function together in a work process, they each bring aspects of their home organization with them, often as expectations of ways of doing business. By identifying organizational cultural characteristics, especially in situations where there has not been an opportunity for the decision-makers to train together and learn each other's processes, the potential effects of mismatches in organizational characteristics can be highlighted. For example, Merritt and Helmreich (1996) found striking differences in the structure and functioning of communications within the cockpit of Asian and U.S. airliners. The ability to communicate, especially in an emergency, might be negatively impacted if a U.S. crewmember were to be assigned to fill a billet in an Asian cockpit or vice versa.

In this research, the model of each work process reflects the organization in which the process is embedded (the host organization). As decision-makers are assigned to billets within the process, relevant dimensions of their home organization (such as vertical or horizontal communication processes) are included as parameters at the nodes. If the home organization is the same as the host organization, then no impact is included. However, if the culture of the home organization is different, then the potential impact upon process performance will be simulated. Through sensitivity analysis, the effect of inserting decision-makers from different organizations to specific nodes will be calculated. This will enhance the ability of planners and commanders to build effective processes in combined operations.

\subsection{The Integrative Decision Space Model}

Multinational coalitions bring together decision-makers with different cultural backgrounds, operating procedures, and decision-making processes. Cultural models may capture the effect of national differences but lack the contribution of the individual's training and experience. Likewise a model of the individual decision-maker may capture his expertise and cultural biases, but it does not capture his role in the organization or the decision process. Different organizational structures also influence the decision process. Moreover, the decision-maker's rank status within the structure affects his performance and the performance of staff with whom he interacts. While these distinct factors that influence the decision process are reasonably well understood in separation, in order to model cultural differences in human decision-making, all components must interact together. In order to understand how these organizational, process, cultural and individual attributes affect coalition operations and collaborative decision-making, a model was developed to incorporate these predispositions into the decision-making process and predict their effect on the interactions that occur between decision-makers.

The Integrative Decision Space Model includes organizational, process, cultural, and decision-maker (individual or team) components. The organizational component contains the hierarchical arrangement of positions that are relevant to the process. This arrangement is very similar to the familiar organization chart that shows lines of formal authority. The process component contains the sequence of tasks in a decision process; 
the tasks are characterized as types of activities that must be performed. The U.S. Department of Labor coding scheme is used to specify these activities. The cultural component specifies dimensional attributes that have been demonstrated to affect decision-making and task completion. The decision-maker component represents either individual or team task performers, depending on the scale of the specified decision process. Example attributes of decision-makers are their training and experience as applicable to the nodes of the process.

The variables represented in each of these component models interact in a decision space where the process is simulated and the effects of the different parameter values influence the process outcomes using the decision space algorithm. The Integrative Decision Space Model provides a description of the decision environment from the organization and process models, and introduces decision-makers with cultural profiles and individual experiences into the decision nodes. The decision space algorithm describes this interaction and allows simulations of a decision process to be executed; component attributes can be varied to view and compare projected performance of the process. The process outcomes that are evaluated are Accuracy, Completeness, and Timeliness. Accuracy is defined as freedom from mistakes or errors, completeness is defined as having no part lacking, and timeliness is defined as coming early or at the correct time. The content of the process output is not evaluated but rather these three attributes that describe how the decision was made. In most processes evaluated, changing component model variables will result in the same output (i.e., the same product will ensue from the process); however these outcome characteristics will be different, reflecting the different decision styles and values. For a complete description of the Integrative Decision Space Model see Handley and Heacox (2003).

\subsection{Organizational Cultural Parameters}

Along with cultural differences based on national culture, individuals or teams also bring to coalition operations the business methods from their home organizations. While national culture is generally defined as a "collective mental programming" of the people of any particular nationality (Hofstede, 1980, 1991), organizational or corporate culture covers many facets of organizational life, such as management styles, appraisals, rewards, and communication styles used by employees. Organizational culture differences may also affect decision-makers as they perform tasks. Including organizational cultural parameters in the Integrative Decision Space Model would allow the prediction of outcome changes for a work process when interacting decision-makers have similar national cultures, such as Canada or the U.K., but whose organizational culture is different. Currently, the Integrative Decision Space Model contains two variables as organizational modifiers - authority distance and interface culture. These parameters have been extended, and the organizational component has been expanded to include parameters to represent the effect of organizational culture on a process that has a decision-maker inserted from an outside organization. The organizational cultural parameters are Authority Distance, Interface Culture, Command Authority, Doctrine and Hierarchical Arrangement. 


\subsection{Authority Distance}

Authority distance refers to the comparison of the current decision-maker's hierarchical position and that of the next decision-maker in the process. The position of the billets occupied by the decision-makers in the organizational hierarchy can be used to determine if information is being passed up, down, or laterally between any two decision-makers. Research suggests that the process of sharing information is affected by boundaries such as rank/status within the organizational hierarchy (Heacox, O'Mara \& Smillie, 1999).

This parameter is currently included in the existing model. No change is made when the next decision-maker is at the same level or below the current decision-maker in the organizational hierarchy. However, the outputs are modified if information is passed up the chain of command. This metric has two possible values: passed laterally or to lower billet, or passed to higher authority. The changes to the output metrics are shown Table 1.

Table 1: Authority Distance Effect on Output Metrics

\begin{tabular}{|l|l|l|l|}
\hline $\begin{array}{l}\text { Output Metric } \\
\text { Authority Distance }\end{array}$ & Accuracy & Completeness & Timeliness \\
\hline Same or Lower & No Change & No Change & No Change \\
\hline Higher & Increase & Increase & Decrease \\
\hline
\end{tabular}

\subsection{Interface Culture}

Interface culture refers to the degree of congruity between the nationality of the current decision-maker and the nationality of the next decision-maker in the process. This is an extension of the current interface culture parameter. Cultural differences between decision-makers have been shown to adversely affect information activities. "Due to different national perceptions, information policies were interpreted and/or applied differently at various levels, thus diminishing the effectiveness of the operation." (Siegel, 1996, p. 11).

The interface culture metric has three possible values: same, low difference (in same Hofstede group such as U.S. and U.K.), or high difference (in different Hofstede groups such as U.S. and France). The changes to the output metrics are shown in the Table 2.

Table 2: Interface Culture Effect on Output Metrics

\begin{tabular}{|l|l|l|l|}
\hline $\begin{array}{l}\text { Output Metric } \\
\text { Interface Culture }\end{array}$ & Accuracy & Completeness & Timeliness \\
\hline Same & No Change & No Change & No Change \\
\hline Low Difference & No Change & No Change & Decrease \\
\hline High Difference & Decrease & Increase & Decrease \\
\hline
\end{tabular}




\subsection{Command Authority}

Command authority or combatant command (COCOM) means owning the forces. Because governments will almost never surrender sovereignty and aspects of command, commanders in peace operations seldom have genuine COCOM over forces not from their own nation. Operational Control (OPCON) allows for maximum control without full command or burden of support, i.e. "long term leasing". It is given for a specific time frame or mission. Tactical Control (TACON) is equivalent to "short-term rental". A commander uses forces without the burden of supporting them, but also knows that they may be reassigned at any time. The effects of multiple lines of command are compounded by the complexity of the authority relationships involved; national governments have to be consulted, either directly or indirectly, on almost all decisions (Alberts \& Hayes, 1995).

Command authority indicates whether the current decision-maker is under the same command and control structure as the next decision-maker in the process. In work processes that involve staff from multiple organizations, multiple relationships concerning command and control affect how the process will flow - e.g. decision-makers who need to report back to their own headquarters for authority slow the flow of activities. In Bosnia, "political sensitivities also led PSYOP personnel to remain under national C2. Based on a 1984 executive directive, the CJIICTF [Combined Joint IFOR (Implementation Force) Information Campaign Task Force] (mostly U.S. personnel) remained under EUCOM C2. Refusal to place US PSYOP forces under NATO C2 led to various problems: All PSYOP units reported to the CJIICTF and not the unit they were attached to. All IIC [IFOR Information Campaign] products were approved at EUCOM before dissemination. It also set a bad precedent for future ops. Following the U.S. example, the Germans also chose to remain under national command and control" (Siegel, 1996, p. 8). This metric has two possible values: same (COCOM) or different as shown in Table 3.

Table 3: Command Authority Effect on Output Metrics

\begin{tabular}{|l|l|l|l|}
\hline $\begin{array}{l}\text { Output Metric } \\
\text { Command Authority }\end{array}$ & Accuracy & Completeness & Timeliness \\
\hline Same & No Change & No Change & No Change \\
\hline Different & No Change & No Change & Decrease \\
\hline
\end{tabular}

\subsection{Doctrine}

Doctrine refers to the degree of agreement between the organizational guiding principles of the current decision-maker with those of the next decision-maker in the process. Different doctrine may contain fundamental differences regarding the degree of information that should be reported, the detail that should be contained in directives, or the degree to which subordinates should take initiative. The potential for confusion is large when people with different training, experience, habits, and expectations of command arrangements must work together (Alberts \& Hayes, 1995). For example, in 
the 36-nation coalition in Bosnia, national differences in public information (PI) concepts - different doctrine and procedures - hindered establishment of a truly multinational public information campaign. The theatre was divided into three multinational divisions (MNDs): southwest, southeast, and north (see Figure 1). Each of these divisions had a PI office, and the doctrine that guided the procedures for the public information officers (PIOs) at each was different.

\section{IFOR DEPLOYMENT}

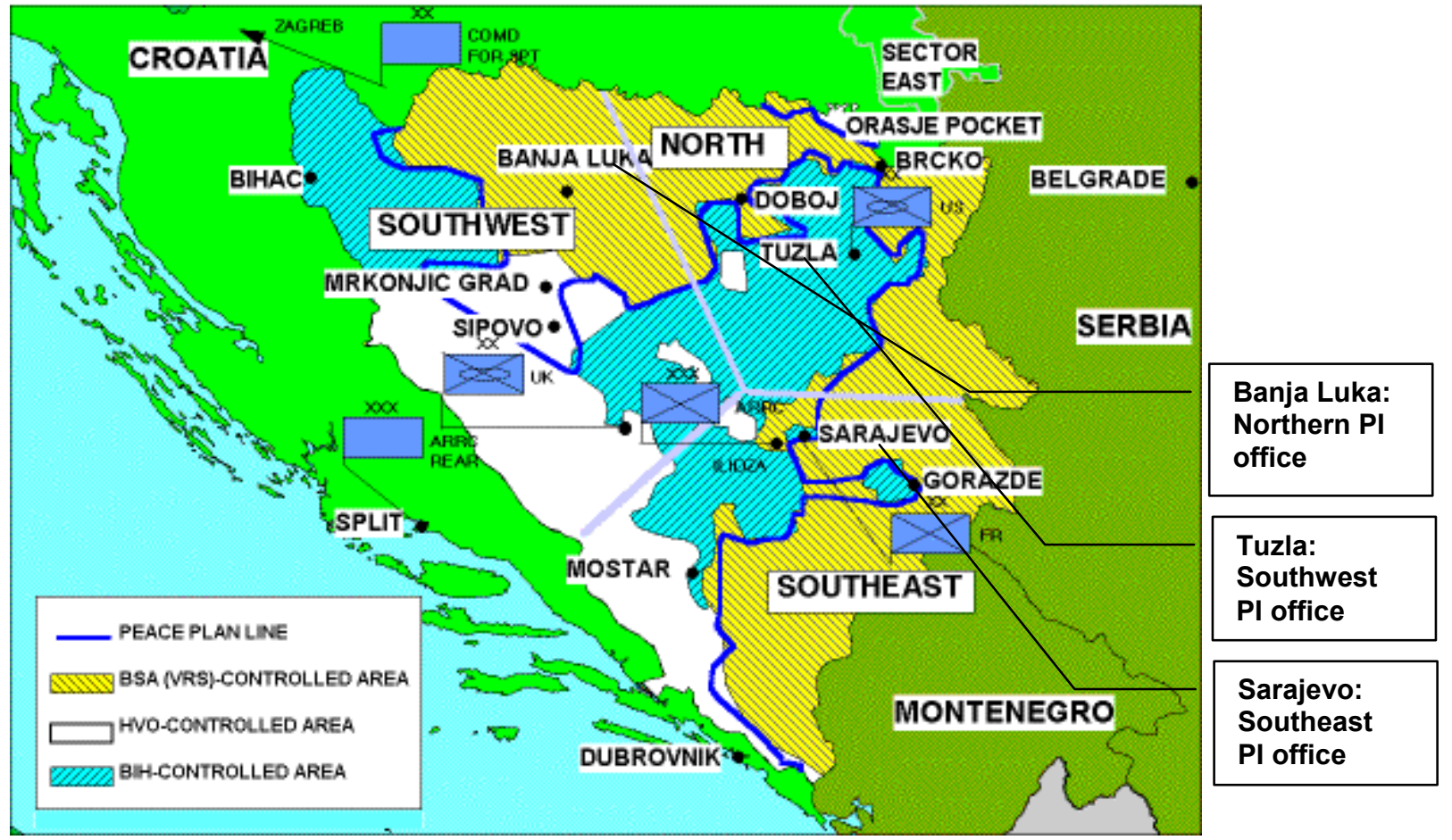

Figure 1: Multinational Divisions in Bosnia (NATO, 1996)

"At MND(SW), PIOs used the UK MOD manual for public information officers to solve problems as they occurred. At $\mathrm{MND}(\mathrm{N})$, the JIB (Joint Information Bureau) mainly worked with U.S. doctrine and according to U.S. procedures.... In October 1996, military photographers videotaped armed RS (Republika Srpska ${ }^{2}$ ) policemen beating up a journalist in the Zone Of Separation. The journalist asked for the tape to be released. At the IFOR [Implementation Force] PI morning meeting, a British officer argued that its release would be contrary to the 'green book' (UK MOD public information directives) instructions, whereas [U.S.] OPLAN 40105 authorized the release" (Siegel, 1998, p. 62).

The doctrine metric also includes attributes of organization type. If two very dissimilar organizations, such as an Non Governmental Organization (NGO) and a Military (MIL) unit were working together, differences in their basic philosophies would be apparent. Hence, the doctrine metric has three possible values: same, different doctrine but same

\footnotetext{
${ }^{2}$ One of the parties in the Dayton Peace Agreement, along with the Republic of Bosnia-Herzegovina, the Bosno-Croat Federation, Croatia, and the Federal Republic of Yugoslavia.
} 
type of organization, or different doctrine and different type of organization. The changes to the output metrics are shown in Table 4.

Table 4: Doctrine Effect on Output Metrics

\begin{tabular}{|l|l|l|l|}
\hline $\begin{array}{l}\text { Output Metric } \\
\text { Doctrine }\end{array}$ & Accuracy & Completeness & Timeliness \\
\hline $\begin{array}{l}\text { Same } \\
\text { (Common Doctrine, } \\
\text { e.g., Joint Doctrine) }\end{array}$ & No Change & No Change & No Change \\
\hline $\begin{array}{l}\text { Different Doctrine, } \\
\text { Same Type Org } \\
\text { (e.g., MIL-MIL) }\end{array}$ & No Change & Decrease & No Change \\
\hline $\begin{array}{l}\text { Different Doctrine, } \\
\text { Different Type Org } \\
\text { (e.g., MIL-NGO) }\end{array}$ & Decrease & Decrease & No Change \\
\hline
\end{tabular}

\subsection{Hierarchical Arrangement}

Hierarchical arrangement refers to the similarity between a decision-maker's home command structure and that of the current work process. Three major types of command arrangements, each with two important subtypes, have been identified. "The key distinction is the level of centralization ${ }^{3}$ required, ranging from the heavily distributed 'control-free' to the inherently centralized 'cyclic' approaches" (Alberts \& Hayes, 1995, p. 84). The three types range from mission-specific through objective-specific to order specific. In Figure 2, directive specificity refers to the level of detail required in the directives issued by headquarters in each type of system, and command approach delineates sub-types.

\begin{tabular}{|c|c|c|c|}
\hline DIRECTIVE SPECIFICITY & COMMAND APPROAC & & EXAMPLE \\
\hline & CONTROL-FREE & --- & WMUIII GERMAN \\
\hline \multicolumn{4}{|l|}{ MISSION-SPECIFIC } \\
\hline & SELECTIVE-CONTROL & --- & ISRAELI ARMYY \\
\hline & PROBLBM-BOUNDING & --- & BRITISH ARMYY \\
\hline \multicolumn{4}{|l|}{ OBJECTIVE- SPECIFIC } \\
\hline & PROBLEM-SOLYNG & --- & U.S. ARMY \\
\hline \multicolumn{4}{|r|}{ MODERN SOMET } \\
\hline & CrCLIC & --- & CHINESE ARMYY \\
\hline
\end{tabular}

Figure 2. Types and Sub-types of Command Arrangements (Alberts \& Hayes, 1995)

\footnotetext{
${ }^{3}$ Centralization means the degree of concentration of authority in an organization. In highly centralized organizations, decision authority is concentrated at upper levels of personnel. In highly decentralized organizations, decision authority is granted to relevant lower level personnel.
} 
The class of mission-specific organizations encompasses the control free and selective control systems. For these organizations, the assumption is that the commander on the scene has been empowered to make decisions. The control-free command center is the most distributed approach. The class of objective-specific organizations assumes some level of trust and initiative in subordinate commands, but stresses synchronization of assets and actions across commands. For problem-solving systems specific directives are given while problem-bounding systems articulate objectives in general terms. Orderspecific systems rely on a central authority to issue directives. The greatest degree of centralization occurs in cyclic systems (Alberts \& Hayes, 1995).

"The existence of these six distinct types of command and control systems in prominent military establishments helps to explain why coalition operations are plagued by interoperability problems at the cultural, organizational, and procedural (doctrinal) levels" (Alberts \& Hayes, 1995, p. 89). The hierarchical arrangement metric has three possible values: same type, decision-maker's home organization is more: frequent (accuracy), detailed (completeness) or centralized (timeliness), or decision maker's home organization is less: frequent (accuracy), detailed (completeness) or centralized (timeliness). The changes to the output metrics are shown in the Table 5.

Table 5: Hierarchical Arrangement Effect on Output Metrics

\begin{tabular}{|l|l|l|l|}
\hline $\begin{array}{l}\text { Output Metric } \\
\text { Hierarchical } \\
\text { Arrangement }\end{array}$ & Accuracy & Completeness & Timeliness \\
\hline Same & No Change & No Change & No Change \\
\hline More & & & \\
\hline Frequent & Increase & & \\
\hline Detailed & & Increase & Decrease \\
\hline Centralized & & & \\
\hline Less & & & \\
\hline Frequent & Decrease & & Increase \\
\hline Detailed & & Decrease & \\
\hline Centralized & & & \\
\hline
\end{tabular}

\subsection{Including Organizational Culture Parameters in the Model}

By including the enhanced organizational cultural parameters, the Integrative Decision Space Model can now predict differences in processes from nationalities that are similar, such as the U.S. and U.K. These organizational parameters exert their impacts directly on outcome criteria, not through cultural dimensions in the decision space algorithm. While the five modifiers are not orthogonal, each captures a unique aspect of the organizational impact. These parameters have been determined from theoretical research, validating them with empirical studies is ongoing. 
In order to execute the Integrative Decision Space Model, the Task Force Falcon (TFF) Public Affairs Office (PAO) News Release Process (Wentz, 2002; Hutton, 2002) is used as an example process. This is a defined process for completing, approving, and distributing news releases with a fully integrated Information Office and other key staff input while maintaining the DoD principles of information. The objective of the process is to achieve an accurate, balanced, and credible presentation of timely information that communicates the commander's intent. This process was chosen because it was well defined, had an associated command structure, and could be validated based on the results of TFF. This process is shown in Figure 3.

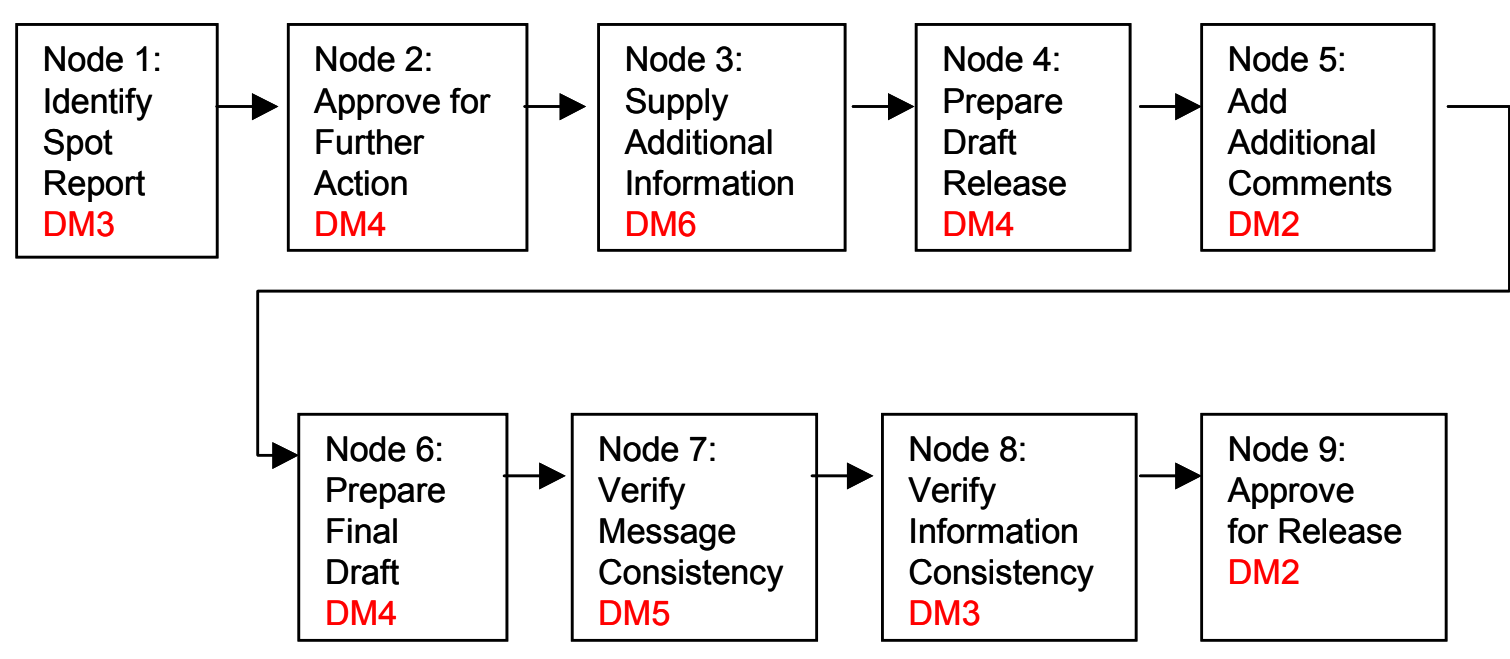

Figure 3: Public Affairs Office News Release Process (Hutton, 2002)

The U.S. and the U.K. have different Public Information Principles. The U.S. believes that it is a democratic requirement to release information because people have a right to know; the U.K. believes that the release of information should serve an operational purpose and that the media doesn't have the right of access to information. This results in different philosophies, which lead to different release 'thresholds.' The U.S.-based policy is to release information unless precluded by troop safety. Information already "obvious to the media" should be confirmed. The U.K.-based policy is to not release information about ongoing or upcoming operations. An example of these different 'release thresholds' due to differing national perceptions was cited above (a release of information about policemen assaulting a journalist was contrary to the UK MOD public information directives, whereas US OPLAN 40105 authorized the release) (Siegel, 1998).

The PAO process shown in Figure 3 can be simulated with the Integrative Decision Space Model with all U.S. decision-makers in order to establish baseline values for the outcome metrics. Then, to illustrate the effect of including the organizational culture parameters, a U.S. decision-maker can be replaced with a U.K. decision-maker to confirm that the model predicts differences as expected, i.e. the different decision thresholds. 
Work processes that involve staff from multiple nations, where the command relationship affects how the task flow will function (i.e., may need to report to their own headquarters for authority), often result in a decrease in the timeliness measure. In the PAO example, another aspect that differs is the nature of information to release (Siegel, 1996). In the PAO process shown above in Figure 3, these effects would present themselves at node 2, which requires an 'approval' to proceed.

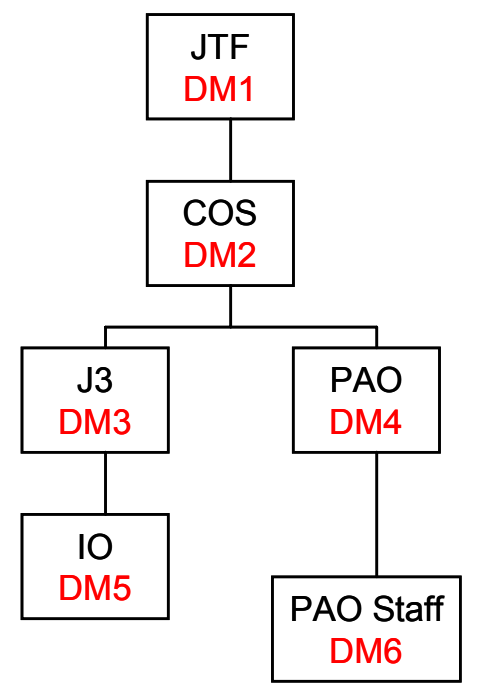

Figure 4: Public Affairs Office Command Structure (Wentz, 2002)

Node 2 is the responsibility of DM4, the PAO, as shown in Figure 4, the command structure. Assigning a U.K. decision-maker to Node 2 ("Approve for Further Action") in the process in Figure 3 also requires assigning the U.K. decision-maker to nodes 4 and 6. By executing the Integrative Decision Space Model and by comparing the output parameters to the baseline U.S. parameters, the reluctance of the U.K. decision-maker to release information can be evaluated. Without the enhanced organizational cultural parameters, the Integrative Decision Space Model would not indicate a difference, since the cultural component model parameters between the U.S. and U.K. are very similar as shown in Table 6.

Table 6: Comparison of U.S. and U.K. National Cultural Differences

\begin{tabular}{|l|l|l|l|l|}
\hline & PD & UA & M & I \\
\hline US & L (40) & L (46) & H (62) & H (91) \\
\hline UK & L (35) & L (35) & H (66) & H (89) \\
\hline
\end{tabular}

Note that the column headers refer to the Hofstede Dimensions (Hofstede, 1980, 1991) of Power Distance (PD), Uncertainty Avoidance (UA), Masculinity (M), and Individuality (I). Hofstede Dimensions are measured on a normalized scale of $1-100$, with 50 being the break point for High $(\mathrm{H})$ scores. For a description of how these dimensions are used in the Integrative Decision Space Model see Handley and Heacox (2003). The baseline 
results $^{4}$ from the Integrative Decision Space Model, using an all-U.S. team, are shown in the Table 7. By substituting the U.K. decision-maker at three of the nodes, the organizational cultural parameters will adjust the values based on the interface between the nodes.

Table 7: Baseline U.S. Values for PAO Process

\begin{tabular}{|l|l|l|l|l|l|l|l|l|l|}
\hline & $\begin{array}{l}\text { Node } \\
1\end{array}$ & $\begin{array}{l}\text { Node } \\
2\end{array}$ & $\begin{array}{l}\text { Node } \\
3\end{array}$ & $\begin{array}{l}\text { Node } \\
4\end{array}$ & $\begin{array}{l}\text { Node } \\
5\end{array}$ & $\begin{array}{l}\text { Node } \\
6\end{array}$ & $\begin{array}{l}\text { Node } \\
7\end{array}$ & $\begin{array}{l}\text { Node } \\
8\end{array}$ & $\begin{array}{l}\text { Node } \\
9\end{array}$ \\
\hline Accuracy & 2 & 0 & 3 & 1 & 2 & 0 & 1 & 1 & 0 \\
\hline Completeness & 4 & 2 & 5 & 3 & 4 & 2 & 3 & 3 & 2 \\
\hline Timeliness & 7 & 6 & 6 & 5 & 7 & 6 & 5 & 5 & 5 \\
\hline
\end{tabular}

The adjustments to the values based on the U.S. - U.K. interface nodes are summarized in Table 8, and Table 9 shows the new attribute values of the nodes after including the organizational parameters in the Integrative Decision Space Model. The organizational parameters will present themselves only at the interface of nodes that have decisionmakers of different organizations, in this case the interface between a U.S. to U.K. or U.K. to U.S. decision-maker. In the PAO process this will be Nodes 1 through 6 . For all nodes passing between "home" (U.S.) and "visitor" (U.K.), the effects of Authority Distance and Interface Culture are felt. However, the effects of Command Authority, Doctrine, and Hierarchical Arrangement are only seen at the nodes where a "visitor "interfaces to a "home" decision maker.

\footnotetext{
4 The number values have no inherent meaning--they are simply metrics used to calculate and compare impacts on the process performance outcomes. Each node has an initial value of zero for each outcome; this value is incremented or decremented through the course of the algorithm -- typical values for node outcomes range from -10 to +10 .
} 
highly active in this process, i.e. responsible for three nodes, there is a greater impact than if he had only a single role in the process. In this case, both the completeness and timeliness parameters decreased. Work processes that involve staff from multiple nations often result in a decrease in the timeliness measure. The decrease in completeness reflects the hesitancy of the U.K. decision-maker to release information.

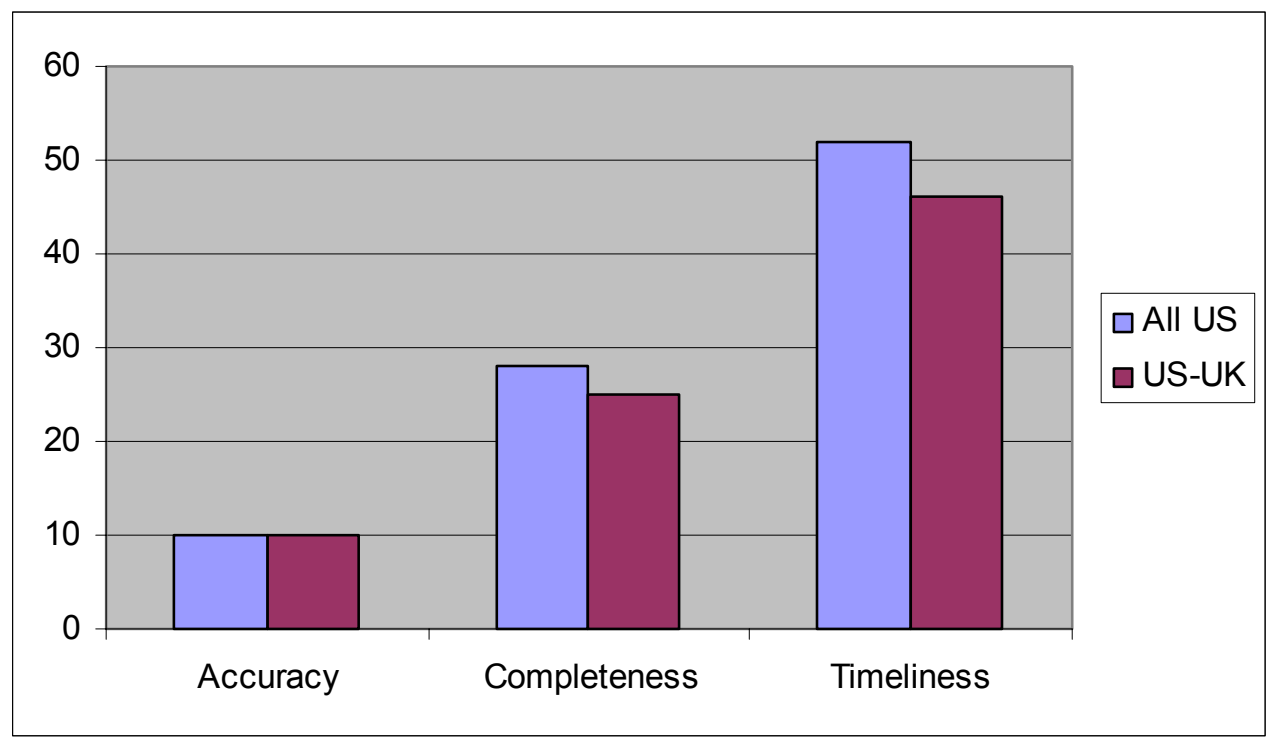

Figure 5: Comparison of Output Attributes

\subsection{Conclusion}

This research identified and included organizational cultural parameters in the Integrated Decision Space Model. A decision-maker is a member of an organization and is accustomed to fulfilling a role in that organization's work process. The organizational culture can be represented by parameters in the work process in which the decisionmaker is participating. Five organizational cultural parameters have been identified: Authority Distance, Interface Culture, Command Authority, Doctrine and Hierarchical Arrangement. Including these organizational cultural parameters in the Integrative Decision Space Model allows the prediction of outcome changes for a work process when interacting decision-makers have similar national cultures but whose organizational culture is different. These organizational parameters exert their impacts directly on outcome criteria. While the five modifiers are not orthogonal, each captures a unique aspect of the organizational impact.

As an example, a PAO process was simulated with the Integrative Decision Space Model with all U.S. decision-makers in order to establish baseline values for the outcome metrics. Then, to illustrate the effect of including the organizational cultural parameters, a U.S. decision-maker was replaced with a U.K. decision-maker to confirm that the model predicts the different decision thresholds anticipated by the different organizational parameters. By identifying organizational cultural characteristics, especially in situations where there has not been an opportunity for the decision-makers to train together and 
learn each other's processes, the potential effects of mismatches in organizational characteristics can be highlighted.

\section{References:}

Alberts, D.S. \& Hayes, R.E. (1995) Command Arrangements for Peace Operations. Washington, DC: NDU Press.

Handley, H.A.H \& Heacox, N.J. (2003). Modeling and Simulation of Cultural Differences in Human Decision Making. San Diego, CA: Pacific Science and Engineering Group.

Heacox, N.J., O’Mara, W. J., \& Smillie, R.J. (1999). Enhancing Unity of Effort in a Virtual Organization. San Diego, CA: Pacific Science and Engineering Group.

Hofstede, G. (1991). Cultures and Organizations, New York, NY: McGraw Hill.

Hofstede, G. (1980). Culture's consequences: International difference in work-related values. Beverly Hills, CA: Sage Publications.

Hutton, J. (2002). "Effective Public Affairs in Peace Operations: Kosovo," CALL: News from the Front, July/August,http://call.army.mil/Products/NFTF/julaug02/hutton.htm.

Merritt, A. C., \& Helmreich, R. L. (1996). "Human factors on the flight deck: The influence of national culture." Journal of Cross-Cultural Psychology, 27(1), 5-24.

NATO, Int. (1996, January 10). IFOR deployment. Retrieved February 3, 2004, from http://www.nato.int/maps/ifor/ifordep1.gif

Siegel, P.C. (1996) Information Activities in the Command and Control of Peace Operations IFOR, Bosnia-Herzegovina, (briefing: http://www.dodccrp.org/siegel1.htm) Vienna, VA: Evidence Based Research, Inc..

Siegel, P.C. (1998) Target Bosnia: Integrating Information Activities in Peace Operations. NATO-Led Operations in Bosnia-Herzegovina, Washington, DC: NDU.

Wentz, L. (2002). Lessons from Kosovo, Washington, DC: CCRP Publications Series. 